\title{
Corrigendum: Why Quorum Sensing Controls Private Goods
}

\author{
Martin Schuster ${ }^{1 *}$, D. Joseph Sexton ${ }^{1}$ and Burkhard A. Hense ${ }^{2 \dagger}$ \\ ${ }^{1}$ Department of Microbiology, Oregon State University, Corvallis, OR, United States, ${ }^{2}$ Institute of Computational Biology, \\ Helmholtz Zentrum München, Neuherberg, Germany \\ Keywords: quorum sensing, cooperation, cheating, public good, private good, evolutionary stability, \\ Pseudomonas aeruginosa, nucleoside hydrolase
}

\section{OPEN ACCESS}

Edited and reviewed by: Wolfgang R. Streit, University of Hamburg, Germany

*Correspondence:

Martin Schuster martin.schuster@oregonstate.edu

${ }^{\dagger}$ Deceased.

Specialty section:

This article was submitted to Systems Microbiology,

a section of the journal Frontiers in Microbiology

Received: 13 June 2017 Accepted: 13 July 2017 Published: 24 July 2017

Citation:

Schuster M, Sexton DJ and Hense BA (2017) Corrigendum: Why Quorum Sensing Controls Private Goods.

Front. Microbiol. 8:1420 doi: 10.3389/fmicb.2017.01420

\section{A corrigendum on}

Why Quorum Sensing Controls Private Goods

by Schuster, M., Sexton, D. J., and Hense, B. A. (2017). Front. Microbiol. 8:885. doi: 10.3389/fmicb. 2017.00885

Here we intend to clarify the function of $r b s D$, a conserved gene involved in bacterial ribose utilization. As stated in the original article, $r b s D$ is absent in P. aeruginosa, which is the likely cause for its slow growth rate on adenosine as a carbon source. Adenosine is cleaved into ribose and adenine by a periplasmic, quorum sensing-dependent nucleoside hydrolase (Nuh). In the section "The case of Nuh," we suggested that rbsD contributes to ribose uptake, based on the original characterization of an rbsD mutant in E. coli (Oh et al., 1999). However, subsequent biochemical studies have revealed a more specific function. E. coli rbs D encodes a ribose mutarotase that catalyzes the conversion between the pyranose and furanose forms of D-ribose immediately after cytoplasmic uptake by the ribose transporter RbsABC (Kim et al., 2003; Ryu et al., 2004). While ribose primarily exists as a pyranose in solution, the furanose is the preferred substrate in the ensuing phosphorylation by the ribokinase RbsK (Sigrell et al., 1998). Thus, the intracellular level of the furanose as a substrate for RbsK may be the growth-limiting factor in $r b s D$-deficient P. aeruginosa.

Irrespective of these biochemical details, however, our main conclusions drawn in the original article remain the same: Adenosine is a relevant nitrogen but not carbon source in the ecology of $P$. aeruginosa. As a carbon source, adenosine does not constrain cheating in native $P$. aeruginosa but rather promotes non-social adaptation during long-term cultivation. 


\section{REFERENCES}

Kim, M.-S., Shin, J., Lee, W., Lee, H.-S., and Oh, B.-H. (2003). Crystal structure of RbsD leading to the identification of cytoplasmic sugar-binding proteins with a novel folding architecture. J. Biol. Chem. 278, 28173-28180. doi: 10.1074/jbc.M304523200

Oh, H., Park, Y., and Park, C. (1999). A mutated PtsG, the glucose transporter, allows uptake of D-ribose. J. Biol. Chem. 274, 14006-14011. doi: 10.1074/jbc.274.20.14006

Ryu, K.-S., Changhoon Kim, C., Kim, I. Yoo, S., Choi, B.-S., and Park, C. (2004). NMR application probes a novel and ubiquitous family of enzymes that alter monosaccharide configuration. J. Biol. Chem. 279, 25544-25548. doi: 10.1074/jbc.M402016200

Sigrell, J. A., Cameron, A. D., Jones, T. A., and Mowbray, S. L. (1998). Structure of Escherichia coli ribokinase in complex with ribose and dinucleotide determined to 1.8 å resolution: insights into a new family of kinase structures. Structure 6, 183-193. doi: 10.1016/S0969-2126(98) 00020-3

Conflict of Interest Statement: The authors declare that the research was conducted in the absence of any commercial or financial relationships that could be construed as a potential conflict of interest.

Copyright (c) 2017 Schuster, Sexton and Hense. This is an open-access article distributed under the terms of the Creative Commons Attribution License (CC $B Y)$. The use, distribution or reproduction in other forums is permitted, provided the original author(s) or licensor are credited and that the original publication in this journal is cited, in accordance with accepted academic practice. No use, distribution or reproduction is permitted which does not comply with these terms. 